\title{
CONSERVAÇÃO PÓS-COLHEITA DE BANANA cv. NANICÃO CLIMATIZADA E COMERCIALIZADA EM CUIABÁ - MT E REGIÃO' ${ }^{1}$
}

\author{
RAQUEL PIRES CAMPOS ${ }^{2}$, JOÃO PEDRO VALENTE ${ }^{3}$, WALTER ESFRAIN PEREIRA ${ }^{4}$
}

\begin{abstract}
RESUMO - A banana cv. Nanicão é a principal cultivar comercializada nos mercados brasileiro e mundial. A maior parte dessa cultivar comercializada no Estado de Mato Grosso vem de outros Estados, embora existam condições edafoclimáticas para ser auto-suficiente na produção dessa cultivar e inclusive atender a outros mercados. O objetivo deste trabalho foi verificar as condições da climatização da banana cv. Nanicão e sua influência na conservação pós-colheita de frutos produzidos no Estado de Mato Grosso (MT) e procedentes do Estado de Santa Catarina (SC). Foram acompanhadas 12 caixas de banana cv. Nanicão, pesando em torno de $21 \mathrm{~kg}$ cada, colhidas em pomar comercial do município de Campo Verde-MT, e também 12 caixas oriundas de SC. Anteriormente à climatização e durante todo o período de vida útil dos frutos, foram monitoradas diariamente a temperatura e a umidade relativa do ambiente, a evolução da coloração dos frutos e a perda de peso destes, assim como o teor de sólidos solúveis totais e de acidez potenciométrica nos frutos verdes e maduros. Verificou-se o maior período de vida útil da banana de SC, 3 dias após a retirada da câmara de climatização, apresentando-se totalmente amarela e com valor máximo de 7,07\% de perda de peso dos frutos. A banana cv. Nanicão produzida no MT atingiu valores de perda de peso $5,69 \%$ no $2^{\circ}$ dia, quando após esse período, não estaria mais própria para a comercialização, atingindo coloração amarelo-pálida. Altos índices de perdas foram detectados no período pós-colheita da banana-'Nanicão', representados principalmente por danos mecânicos na procedente de SC e por danos fisiológicos (despencamento) na banana de MT. O despencamento pode estar relacionado com a falta de circulação eficiente do etileno, da exaustão e umidade relativa baixa, $65 \%$ em média, durante a climatização. Nos teores de açúcares e de acidez dos frutos, a banana do MT apresentou valores levemente superiores de acidez, o que favorece o seu sabor quando relacionado com os teores de açúcares.
\end{abstract}

Termos para Indexação: Musa spp., maturação controlada, vida útil

\section{POSTHARVEST OF BANANA 'NANICÃO’ PRODUCED IN THE STATES OF MATO GROSSO AND SANTA CATARINA, MARKETED IN CUIABÁ -MT}

\begin{abstract}
The banana cv. Nanicão is the main cultivated and marketed in the Brazilian and world markets. Most of this banana marketed in the State of Mato Grosso comes from another States, and Mato Grosso presents edaphoclimatic conditions to be sufficient in the production of this cultivar and besides to assist other markets. The objective of this work it was to verify the conditions of the climatization of bananas cv. Nanicão and its influence in the post harvest conservation of fruits produced in Mato Grosso (MT) and coming from Santa Catarina State (SC). Twelve boxes were accompanied, weighting around $21 \mathrm{~kg}$ of bananas cv. Nanicão picked in the municipal district of Campo Verde-MT, in commercial orchard and also 12 boxes originated from SC. Previously of the climatization period, and during the whole period of useful life of the fruits, the temperature and relative humidity, the evolution of the coloration of the fruits and their weight loss, the total soluble solids and titratable acidity in the green and mature fruits were monitored. The largest period of useful life of banana coming from SC was verified, 3 day after the retreat of the climatization camera, turning totally yellow and with maximum values of 7,07\% of loss of fruit weight. The banana cv. Nanicão produced in MT reached values of weight loss 5,69\% in the 2nd day, when after that period it would not be appropriated for commercialization. The coloration of the fruits developed to yellow, and in some bunches they continued with green points, while other already began the senescence (brown points), being this smaller difference in bananas of MT, which reached a paler yellow coloration. These alterations can be related, respectively, with the lack of efficient circulation of the ethylene and the low relative humidity, around $65 \%$, during the climatization.
\end{abstract}

Index terms: Musa spp., maturation, shelf life.

Embora o Brasil seja o maior produtor mundial de banana, exporta menos que 3\% do total produzido, e a maior parte da produção é destinada ao consumo in natura (Pino et al., 2000).

Com a globalização da economia, as perspectivas de produção e comercialização de frutas tropicais são excelentes. A banana-'Nanicão' apresenta grande potencial de aceitação e expansão no Estado de Mato Grosso, embora muitos comerciantes tenham preferência por essa cultivar produzida em outros Estados, principalmente, Santa Catarina.

Por ser um fruto climatérico, a banana apresenta respiração muito ativa, responsável por uma série de transformações bioquímicas e fisiológicas durante seu amadurecimento. Os frutos são colhidos ainda verdes, no estádio de completo desenvolvimento fisiológico indicado, nessa cultivar, pelo desaparecimento das quinas dos frutos (Bleinroth et al., 1992).

As qualidades alimentícias e comerciais da banana são influenciadas pelas condições de amadurecimento e armazenamento, sendo necessária a indução do amadurecimento em câmaras de maturação controlada, também denominada de climatização. Nesse sentido, vários fatores devem ser controlados, dentre os quais, temperatura, umidade relativa, gás ativador de maturação, ar atmosférico, circulação de ar e exaustão, visando à melhor uniformização no grau de amadurecimento e comercialização dos frutos.
Chitarra \& Chitarra (1984) afirmam que, quando a temperatura da polpa é muito baixa $\left(<16^{\circ} \mathrm{C}\right)$ ou muito alta $\left(>22^{\circ} \mathrm{C}\right)$ durante a climatização, resultam em frutos com cor pobre, deficientes na cor amarela, e temperaturas inferiores a $12^{\circ} \mathrm{C}$ causam danos pelo frio à fruta.

A umidade relativa de $85-90 \%$, com a câmara fechada, evita o murchamento, a perda excessiva de peso da banana, e quando associada a temperaturas adequadas, contribui para melhorar o aspecto, a comerciabilidade e a vida útil das bananas (Moreira, 1987). Borges (1997) também indica que a manutenção da umidade relativa deve ser entre 85 e $95 \%$ durante a maturação controlada.

O etileno $\left(\mathrm{C}_{2} \mathrm{H}_{4}\right)$ é um dos componentes químicos mais simples empregados para o amadurecimento de banana, e a taxa normal de etileno requerido em câmaras é cerca de 10 ppm (Moreira,1987).

A circulação do ar nas câmaras mantém a distribuição homogênea do ar e do gás ativador e a temperatura constante, evitando a formação de camadas de vapor d'água, gás carbônico e componentes voláteis ou de película microscópica de água na superfície das frutas, que impedem tanto a saída do $\mathrm{CO}_{2}$ como a entrada do gás ativador, funções estas necessárias para o amadurecimento das frutas (Bleinroth, 1993). A renovação do ar pode ser feita pela abertura da porta da câmara, por variação na pressão

\footnotetext{
(Trabalho 040/2002). Recebido: 09/03/2002; Aceito para publicação: 26/09/2002.

${ }^{2}$ Eng. Agr. Sc. Laboratório de Tecnologia de Alimentos, Faculdade de Agronomia e Medicina Veterinária (FAMEV), UFMT, Av. Fernando Corrêa da Costa, s/n, CuiabáMT, CEP 78068-900. Tel. (65) 615-8601.

${ }^{3}$ Eng. Agr. D. Sc., Professor Adjunto - FAMEV/UFMT.

${ }^{4}$ Eng. Agr. D. Sc., Bolsista DCR do CNPq - FAMEV/UFMT. e-mail:wep@bol.com.br.
} 
atmosférica ou por infiltração de ar (Chitarra \& Chitarra, 1990).

$\mathrm{O}$ aumento característico na respiração, combinado com outros fatores, principalmente ambientais, como a temperatura e umidade relativa, acelera certos processos como a transpiração e produção de etileno que reduzem a vida útil do fruto, devido à perda de qualidade e à rápida deterioração (Finger et al., 1995).

As principais causas de perdas de frutas in natura são, de modo geral, causas fisiológicas, caracterizadas pela perda excessiva de umidade associada à temperatura de armazenamento, gases como o $\mathrm{CO} 2$, ausência do pré-resfriamento do produto e acúmulo de etileno; causas fitopatológicas, relacionadas à alta suscetibilidade das frutas ao ataque de microorganismos e causas mecânicas, como corte, compressão, impacto e vibração, são os principais responsáveis por lesões às frutas (Bleinroth et al., 1992).

O objetivo deste trabalho foi comparar os aspectos relacionados à pós-colheita de banana cv. Nanicão produzida em Mato Grosso e Santa Catarina, climatizada e comercializada em Cuiabá-MT, verificando as condições de climatização e sua influência na qualidade dos frutos e no período de conservação pós-colheita destes.

Num primeiro experimento (setembro/2000), bananas-'Nanicão' procedentes de Santa Catarina, transportadas em caminhões refrigerados a $13^{\circ} \mathrm{C}$, durante 48 horas, em caixas de madeira tipo torito, foram diretamente para a câmara de climatização da Krausburg Distribuidora de Frutas, em Várzea Grande-MT. Num segundo experimento (outubro/2000), bananas cv. Nanicão, produzidas em pomar comercial do município de Campo Verde-MT, foram transportadas em caixas plásticas para essa Distribuidora. Na maturação controlada, o procedimento utilizado foi o empilhamento de caixas, com a temperatura da câmara a $16^{\circ} \mathrm{C}$ e aplicação de etileno hidratado $(10 \mathrm{ppm})$, durante três dias, para acelerar o amadurecimento.

Em cada experimento, foram escolhidas ao acaso 12 caixas, pesando em torno de $21 \mathrm{~kg}$ cada e submetidas às seguintes avaliações:

- Acompanhamento da perda de peso dos frutos - através de pesagens em balança eletrônica com capacidade de $30 \mathrm{~kg}$ e precisão de $5 \mathrm{~g}$;

- Acompanhamento da coloração dos frutos - através do sistema de notas retirado de Chitarra \& Chitarra, 1990: Verde (1); Verde com traços amarelos (2); Mais verde que amarelo (3); Mais amarelo que verde (4); Ponta verde (5); Todo amarelo (6); Amarelo com áreas café (7).

- Quantificação e qualificação das perdas pós-colheita - os frutos danificados, não prestando para a comercialização, foram quantificados em peso de produto no final do experimento, expressos em porcentagem e classificados como danos mecânicos (amassamento), fisiológicos (excesso de amadurecimento e despencamento) e fitopatológicos (necrose).

Utilizando-se de frutos verdes (antes da climatização) e maduros (após a climatização) escolhidos aleatoriamente, foram realizadas as seguintes análises:

- Sólidos solúveis totais - determinação através do auxílio de refratômetro portátil, e expresso em ${ }^{\circ}$ Brix;

- Acidez titulável - determinação através da titulação com $\mathrm{NaOH}$ $0,1 \mathrm{~N}$ com auxílio de potenciômetro a pH de 8,1 e expressa em $\mathrm{g}$ de ácido málico/100g de polpa.

A partir da câmara de climatização até o último dia de vida útil dos frutos, foram realizadas medições da temperatura, expressa em graus centígrados, e da umidade relativa do ar atmosférico, expresso em porcentagem, nos períodos da manhã e da tarde, através da utilização de Termoigrômetro portátil.

Através da análise estatística não paramétrica de Kruskal-Wallis, os resultados da evolução da perda de peso e da coloração não diferiram estatisticamente nas bananas produzidas nos Estados de Santa Catarina e Mato Grosso (Tabelas 1 e 2).

Verificou-se o maior período de vida útil da banana vinda de SC, apresentando valores máximos de 7,07\% de perda de peso dos frutos em 3 dias após a climatização. A banana cv. Nanicão produzida no MT atingiu $5,69 \%$ de perda de peso em 2 dias. Esse período também foi encontrado por Medina et al. (1996), os quais observaram que o tempo de comercialização (intervalo entre a cor seis e a cor oito da casca) de banana-'Nanica', dentre outras cultivares, foi muito curto, variando entre 2 e 4 dias.
Embora as bananas provenientes de SC e MT tenham sido retiradas da câmara de climatização após três dias, apresentaram médias de coloração diferentes, nota 4 e 1,52, respectivamente (Tabela 1), e a coloração dos frutos de MT diferiu significativamente no $1^{\circ}$ e $2^{\circ}$ dias após a retirada da climatização (Tabela 2).

TABELA 1- Análises físicas em banana- 'Nanicão' produzida nos Estados de Santa Catarina e Mato Grosso, durante o seu amadurecimento

\begin{tabular}{ccccc}
\hline Origem & \multicolumn{2}{c}{ Perda de peso (\%) } & \multicolumn{2}{c}{ Cor (1-7) } \\
\hline & SC & MT & SC & MT \\
Climatização & 2,16 & 1,52 & 4 & 1,52 \\
$1^{\circ}$ dia $^{\circ}$ & 4,15 & 3,05 & 5,33 & 3,05 \\
$2^{\circ} \mathrm{dia}^{\circ}$ & 5,77 & 5,69 & 5,75 & 5,69 \\
$3^{\circ} \mathrm{dia}^{\circ}$ & 7,07 & - & 6,96 & - \\
\hline
\end{tabular}

TABELA 2- Comparações múltiplas entre classes determinadas através do Teste de Kruskal-Wallis, apresentando diferença mínima significativa entre 1 e $5 \%$ de probabilidade, para perda de peso e coloração na pós-colheita de banana-'Nanicão', na região de Cuiabá-MT

COMPARAÇÕES MÚLTIPLAS PERDADE PESO COLORAÇÃO

\begin{tabular}{|c|c|c|c|c|}
\hline \multirow[b]{2}{*}{ the } & \\
\hline & $\mathbf{S C}$ & $\overline{\text { MT }}$ & $\mathbf{S C}$ & $\mathbf{M T}$ \\
\hline 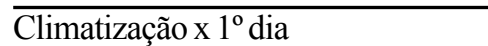 & NS & NS & NS & $* *$ \\
\hline Climatização x $2^{\circ}$ dia & $*$ & $*$ & $* *$ & $*$ \\
\hline Climatização x $3^{\circ}$ dia & $*$ & - & $*$ & - \\
\hline $1^{\circ} \operatorname{dia} \times 2^{\circ}$ dia & NS & $*$ & NS & $* *$ \\
\hline $1^{\circ} \operatorname{dia} \times 3^{\circ}$ dia & $* *$ & - & $* *$ & - \\
\hline $2^{\circ} \operatorname{dia} \times 3^{\circ}$ dia & NS & - & NS & - \\
\hline Climatização SC x Climatização MT & \multicolumn{2}{|c|}{ NS } & \multicolumn{2}{|c|}{ NS } \\
\hline $1^{\circ} \operatorname{dia} \mathrm{SC} \times 1^{\circ} \operatorname{dia} \mathrm{MT}$ & \multicolumn{2}{|c|}{ NS } & \multicolumn{2}{|c|}{ NS } \\
\hline $2^{\circ} \operatorname{dia} \mathrm{SC} \times 2^{\circ}$ dia MT & \multicolumn{2}{|c|}{ NS } & \multicolumn{2}{|c|}{ NS } \\
\hline $3^{\circ} \operatorname{dia} \mathrm{SC} \times 2^{\circ}$ dia MT & \multicolumn{2}{|c|}{ NS } & \multicolumn{2}{|c|}{ NS } \\
\hline
\end{tabular}

* Diferença significativa a $1 \%$ de probabilidade.

** Diferença significativa a $5 \%$ de probabilidade.

A média da coloração dos frutos produzidos no MT não atingiu a nota 6 (amarelo), e vale ressaltar o relatado por Rocha (1984), onde a gradual destruição da clorofila permite que os carotenóides se tornem mais evidentes, e que a coloração da casca é importante fator na determinação da qualidade do produto a ser comercializado. Algumas pencas continuaram com as pontas esverdeadas, enquanto outras já iniciavam a senescência (pontos marrons) e apresentaram uma coloração amarela mais pálida. Segundo Bleinroth (1991), a não-obtenção da cor característica de fruta madura, permanecendo um tanto esverdeada, se deve à quantidade reduzida de oxigênio durante a maturação controlada.

Essas alterações na coloração dos frutos podem estar relacionadas também com a falta de padronização das pencas (na mesma caixa pencas da base e da ponta do cacho), a falta de circulação eficiente do etileno, além da umidade relativa baixa durante a climatização, valores abaixo de 70\% (Tabela 4). Esses dados de umidade relativa são muito inferiores aos considerados por Moreira (1987) e Borges et al. (1997), que relatam a importância da manutenção da umidade relativa entre 85 e $95 \%$ durante a maturação controlada para a obtenção de frutos com boa qualidade de cor e sabor, e enfatizam a necessidade do empilhamento adequado das caixas de banana na câmara para evitar problemas, como casca opaca e polpa excessivamente mole.

A banana-'Nanicão' oriunda de SC apresentou perdas mais expressivas devido a danos mecânicos $(34,09 \%)$, sendo dificilmente controlados devido, principalmente, a distância percorrida e, somada à perda de peso por transpiração, totalizou $42,41 \%$ de perdas (Figura 1). Segundo Dadzie \& Orchard (2001), o dano mecânico é um dos maiores fatores ligados à deterioração pós-colheita da banana.

Nos frutos produzidos em MT, as maiores perdas ocorreram com o excesso de amadurecimento e despencamento dos frutos, 
inviabilizando a comercialização (32,95\%), contabilizando, juntamente com a perda de peso, um alto valor total de perdas de $41,72 \%$. Segundo a FAO (1987), as perdas causadas por danos fisiológicos intensificamse quando ocorrem condições que aceleram o processo natural de deterioração, como temperaturas elevadas, baixa umidade e lesões físicas.

TABELA 4- Monitoramento da temperatura e umidade relativa durante a climatização e no período de vida útil de bananas cv. Nanicão, oriundas dos Estados de Santa Catarina (SC) e Mato Grosso (MT)

\begin{tabular}{ccccc}
\hline Período & \multicolumn{2}{c}{$\mathbf{T}^{\circ} \mathbf{C}$} & \multicolumn{2}{c}{ UR (\%) } \\
& SC & MT & SC & MT \\
\hline Climatização* & 22,8 & 25,3 & 67,2 & 65,0 \\
$4^{\circ}$ dia Tarde & 26,8 & 26,0 & 63,0 & 56,0 \\
$5^{\circ}$ dia Manhã & 24,8 & 28,0 & 62,0 & 66,0 \\
Tarde & 25,1 & 30,5 & 62,0 & 62,0 \\
$6^{\circ}$ dia Manhã & 28,1 & 27,9 & 72,0 & 69,0 \\
Tarde & 27,9 & 29,4 & 54,0 & 67,0 \\
$7^{\circ}$ dia Manhã & 28,2 & - & 77,0 & - \\
Tarde & 24,3 & - & 84,0 & - \\
\hline
\end{tabular}

*A câmara fechada e estabilizada apresentava temperatura de $16^{\circ} \mathrm{C}$.

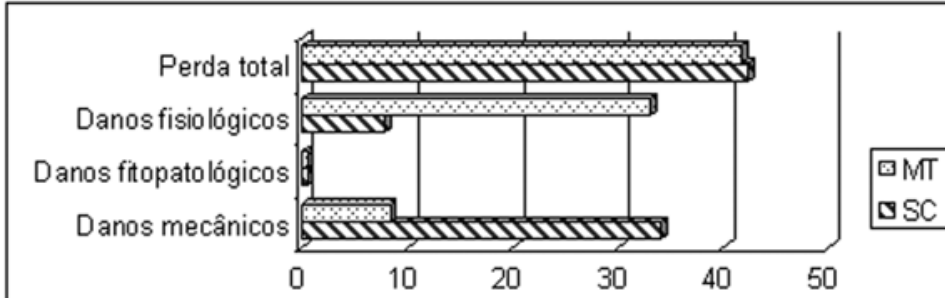

$(\%)$

FIGURA 1- Ocorrência de perdas pós-colheita (PPC) em banana-'Nanicão' oriunda dos Estados de Mato Grosso (MT) e Santa Catarina (SC), climatizada e comercializada em Cuiabá-MT, e região

O despencamento nos frutos de MT também pode estar relacionado com o excesso de abertura da câmara de maturação controlada, atingindo temperatura da câmara durante o amadurecimento levemente superior a $21^{\circ} \mathrm{C}$ e ocasionando polpa mole da banana, com aumento dos danos mecânicos e menor durabilidade (Hall, 1967) e, segundo Moreira (1987), está associado à presença de gás carbônico nas câmaras, impedindo a evolução da coloração, causando rompimento junto ao pedúnculo e retardando o processo de amadurecimento da banana

$\mathrm{O}$ fato de a banana oriunda de SC não apresentar o problema de despencamento, faz-nos crer que o agravante desse dano fisiológico se deve à ausência de pré-resfriamento da banana produzida em MT anteriormente à climatização, permitindo alta atividade metabólica dos frutos no interior da câmara até que a temperatura adequada seja atingida. Segundo Bleinroth et al. (1992), o pré-resfriamento dos frutos evita um aquecimento excessivo na câmara em seguida ao carregamento e o aumento de dióxido de carbono produzido pela respiração destes.

A adequação das condições de climatização (temperatura, umidade relativa, circulação e exaustão do ar), o resfriamento dos frutos produzidos no MT anteriormente a sua colocação na câmara e a maior umidade relativa no ambiente de comercialização contribuiriam para a melhoria da qualidade dos frutos e o aumento da sua vida pós-colheita, além da redução das perdas.

A banana de MT apresentou teores levemente superiores de acidez no final do amadurecimento em relação aos frutos de $\mathrm{SC}(0,350 \mathrm{e}$ $0,307 \mathrm{~g}$ de ácido málico/100 g de polpa, respectivamente), o que favorece o seu sabor, quando relacionado com os açúcares $\left(24,20\right.$ e $25,35^{\circ}$ Brix, respectivamente), indicando a semelhança da qualidade dos frutos produzidos nos dois Estados (Tabela 3). Valores próximos de acidez titulável foram encontrados por Paiva et al. (1996), entre 0,250 e 0,435\% de ácido málico, em banana-'Nanicão' comercializada em Porto Alegre-RS.

Como considerações finais, destacam-se a reduzida vida útil da banana-'Nanicão' climatizada e comercializada na região de Cuiabá-MT, três dias a oriunda de Santa Catarina e dois dias a produzida em Mato Grosso, com altos índices de perdas pós-colheita representados principalmente por danos mecânicos e por danos fisiológicos, respectivamente. A perda de peso, por transpiração, dos frutos provenientes de SC e de MT atingiram valores máximos de 7,07\% e 5,69\%, respectivamente, sendo que os teores de acidez titúlavel e sólidos solúveis totais foram semelhantes. As condições da climatização interferiram na vida pós-colheita da banana cv. Nanicão, principalmente nos frutos produzidos em MT.

TABELA3- Teor de sólidos solúveis totais (SST) e acidez titulável (AT) em banana-'Nanicão' produzida nos Estados de Santa Catarina (SC) e Mato Grosso (MT), durante o seu amadurecimento

\begin{tabular}{|c|c|c|c|c|}
\hline \multirow[t]{2}{*}{ Período } & \multicolumn{2}{|c|}{ SST $\left({ }^{\circ}\right.$ Brix $)$} & \multicolumn{2}{|c|}{ AT (g de ác. málico/100g de polpa) } \\
\hline & SC & MT & SC & MT \\
\hline Inicial & 3,72 & 4,10 & 0,175 & 0,097 \\
\hline Final & 25,35 & 24,20 & 0,307 & 0,350 \\
\hline
\end{tabular}

\section{REFERÊNCIAS BIBLIOGRÁFICAS}

BLEINROTH,E. W.Matéria-prima. In:MEDINA, J.C.;BLEINROTH,E.W.; de MARTIN, Z. J. Banana: cultura, matéria-prima, processamento e aspectos econômicos. 2. ed. Campinas: ITAL, 1993.302p.(Frutas Tropicais, 3).

BLEINROTH, E. W., SIGRIST, J. M. M., ARDITO, E. de F. G. et al. Tecnologia de pós-colheita de frutas tropicais. 2 . ed. rev. Campinas: ITAL, 1992. 203 p. (Manual Técnico, 9).

BLEINROTH, E. W. Determinação do ponto de colheita, maturação e conservação das frutas. In: SOLER, M. P.; BLEINROTH, E. W; IADEROZA, M. et al. Industrialização de frutas. Campinas: ITAL/ Rede de Informação de Tecnologia Industrial Básica, 1991. 206 p. (Manual Técnico, 8).

BORGES, A. L.;ALVES, E. J.; SILVA, S. deO. etal. O cultivo da banana. Cruz das Almas: EMBRAPA-CNPMF, 1997. 109 p. (Circular técnica, 27)

CHITARRA, M, I. F.; CHITARRA, A. B. Pós- colheita de frutos e hortaliças: fisiologia e manuseio. Lavras: ESAL/FAEPE, 1990. 320 p.

CHITARRA. A. B.; CHITARRA, M. I. F. Manejo pós- colheita e amadurecimento comercial de banana. Pesquisa Agropecuária Brasileira, Brasília, v.19.n. 6, p. 761-771. 1984.

DADZIE, B. K.; ORCHARD, J. E. Routine post-harvestscreening of banana/plantain hybrids: criteria and methods. In: INIBAP Technical Guidelines. France: CIRPAC, 2001. 75p.

FAO Manual para el mejoramiento del manejo poscosecha de frutas e hortalizas. Oficina Regional de LAFAO para américa latina y el caribe, Santiago, Chile, 1987. Disponível em: <www.fao.org/inpho/vlibrary/ xoo55s/Xoo55SOO.htm>. Acesso em: 22 out. 2001

FINGER, F. L.; PUSCHMANN, R.; BARROS, R. S. Effects of water loss on respiration, ethylene production and ripening of banana fruit. Revista Brasileira de Fisiologia Vegetal, Brasília, v. 7, n.1, p. 95-114, 1995.

MEDINA,V.M. Climatização da banana. Revista Brasileira de Fruticultura, Cruz das Almas, v. 18, n. 1, p. 43-53,abr., 1996.

MOREIRA, R. S. Banana: teoria e prática de cultivo. Campinas: Fundação Cargill, 1987.368p.

PAIVA, M. C.; CARVALHO, R. I. N. de; FIORAVANÇO, J. C.; MANICA,I. Características da banana- 'Nanicão' comercializada em Porto Alegre de outubro/91 a julho/92. Ciência e Agrotecnologia, Lavras, v.20, n.3, p. 275-278, 1996.

PINO, F. A.; FRANCISCO, V. L. F. dos S.; PEREZ, L. H.; AMARO, A. A. A cultura da banana no Estado de São Paulo. Informações Econômicas, São Paulo, v.30, n.6, 2000.

ROCHA, J. L. V. da. Fisiologia pós-colheita de banana. In: SIMPÓSIO BRASILEIRO SOBRE BANANICULTURA, 1.,1984. Jaboticabal. Anais... Jaboticabal: FCAV/UNESP, 1984. 400p.

SGARBIERI, V. C.; FIGUEIREDO, I. B. Transformações bioquímicas da banana durante o amadurecimento. Revista Brasileira de Tecnologia, São Paulo, v.2, p.85-94, 1971. 